\title{
Relationship of Forgiveness and Feeling of Loneliness with Attitudes toward Marital Infidelity Regarding the Moderating Role of Marital Satisfaction in Married Students
}

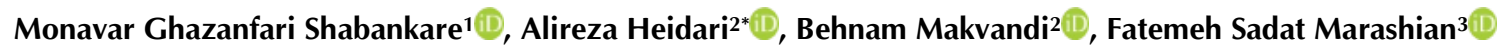 \\ 1 PhD Candidate, Department of Psychology, Ahvaz Branch, Islamic Azad University, Ahvaz, Iran \\ 2 Associate Professor, Department of Psychology, Ahvaz Branch, Islamic Azad University, Ahvaz, Iran \\ 3 Assistant Professor, Department of Psychology, Ahvaz Branch, Islamic Azad University, Ahvaz, Iran
}

\author{
*Corresponding author: \\ Alireza Heidari, Department of \\ Psychology, Ahvaz Branch, Islamic \\ Azad University, Ahvaz, Iran \\ Tel: +986133348420 \\ Email: heidaria945@gmail.com
}

Received: 02 Jun. 2020

Accepted: 26 Aug. 2020

ePublished: 01 May. 2021

\begin{abstract}
Background and Objective: Marital infidelity is a major factor that affects the strength, durability, and mental health of families. The present study aimed to investigate the mediating role of marital satisfaction in the causal relationships between forgiveness and the feeling of loneliness with attitudes toward marital infidelity in married students.

Materials and Methods: This causal-correlational and field study was conducted on 211 married students who were selected from Ahvaz Branch, Islamic Azad University, Ahvaz, Iran, during the academic year 2018-2019 through convenience sampling. The data were collected using the Interpersonal Forgiveness Inventory, Russell's Loneliness Scale, Whatley's Attitude towards Infidelity Scale, and ENRICH marital satisfaction questionnaire. Furthermore, the data analysis was performed in SPSS software (version 24) through descriptive and inferential statistics, including mean \pm SD, Pearson's correlation, and path analysis.

Results: A direct and negative relationship was observed between forgiveness and attitudes toward marital infidelity $(\beta=-0.181, P=0.013)$; feeling of loneliness and marital satisfaction $(\beta=-0.252$, $P=0.001)$; and marital satisfaction and attitudes toward marital infidelity $(\beta=-0.418, P=0.001)$. Furthermore, there was a direct and positive relationship between forgiveness and marital satisfaction $(\beta=0.517, P=0.001)$. Eventually, there was no significant direct relationship between the feeling of loneliness and attitudes toward marital infidelity $(\beta=-0.029, P=0.652)$. The results of path analysis indicated that marital satisfaction had a mediating role in the relationship between forgiveness and attitude towards marital infidelity $(\beta=-0.165, P=0.001)$, as well as the association between the feeling of loneliness and attitude towards marital infidelity $(\beta=0.138, P=0.002)$.

Conclusions: The results showed a good fit for the proposed model in this study. Moreover, marital satisfaction played an important role in the relationship between forgiveness and the feeling of loneliness with the attitude toward marital infidelity.
\end{abstract}

Keywords: Extramarital relationships, Forgiveness, Loneliness, Satisfaction

\footnotetext{
Keywords: Extramarital relationships, Forgiveness, Loneliness, Satisfaction
}

\section{Background}

Various factors, including marital infidelity, affect family stability and durability. Marital infidelity is defined as the individual transition from a marital relationship by establishing a physical or emotional intimacy with a person outside the relationship. In other words, marital infidelity is a breach of contract in a relationship or any conduct that results in failures to perform any promises made by two persons [1]. Attitude toward marital infidelity can be indicative of the emotional and sexual infidelity of males or females to their spouses. Robles et al. [2] reported a positive and significant relationship between emotion seeking and attitudes toward marital infidelity. Furthermore, there was a significant negative association between the quality of relationship and attitude toward marital infidelity. Social factors affecting married women's infidelity included lack of social support from the spouse, inappropriate use of social media, social traumas (e.g., violence and addiction), personality and biological gaps, and weak religious beliefs [3].

Forgiveness is an intrapersonal process through which one's cognition, emotions, and behavior change against wrongs and wrongdoers. Moreover, this process reduces isolation, anger, and revenge, enhances positive emotions, and replaces them with negative emotions [4]. Kerlin [5] reported that attachment styles, personality traits, and forgiveness could predict attitude towards meta-martial relationships. Russell et al. [6] found that reality therapy was effective in promoting forgiveness and that the marital adjustment of women was affected by the infidelity of their spouse. Loneliness is a response to the lack of a satisfying positive 
relationship with others and may lead to marital infidelity in couples. In addition, it is a complex psychological construct and a state in which people perceive or experience a lack of relationships with others.

The key elements of loneliness include the unfavorable feeling of loss, loss of companionship, unpleasant and negative aspects of lost relationships (e.g., sadness and regret), and loss of high-quality relationships with others [7].

According to Isanejad and Bagheri [8], the feeling of loneliness played the highest role in explaining marital infidelity. Similarly, McNulty [9] reported a positive significant relationship between the feeling of loneliness and the tendency toward infidelity. In another study, Renna et al. [10] showed that the compassion-based intervention reduced the feelings of loneliness and increased emotional regulation in individuals with high levels of chronic distress.

Marital satisfaction is another factor that may be related to attitudes toward marital infidelity in couples, and it is defined as the extent to which the couples are happy with the fulfillment of their needs by their partners [11]. Moreover, marital satisfaction is a situation in which husband and wife often feel happy and satisfied with marriage and with each other. In other words, marital satisfaction is the subjective criterion through which it is possible to assess to what extent the couples' needs and desires are fulfilled [12]. Marital relationships and spouses' satisfaction are influenced by many factors and challenged by their multi-faceted nature. In addition, marital infidelity causes the maximum damage to the relationship between husband and wife [13]. A study conducted by McNulty et al. [14] revealed a significant relationship between marital infidelity and factors, such as sexual satisfaction, marital satisfaction, couple relationships, marriage duration, religious beliefs, and conflict resolution.

Given the increasing incidence of extramarital relationships and growing positive attitude towards marital infidelity phenomenon in different societies, including Iran, it is necessary to identify and explain this experience in the cultural and religious context of Iran in order to provide an appropriate, effective, and localized solution for the prevention of this problem. This solution should help therapists better understand clients with such attitudes. Based on the aforementioned cases, the present study raised the question of whether there was a causal relationship between forgiveness and feeling of loneliness with attitudes towards marital infidelity regarding the mediating role of marital satisfaction in married students.

\section{Objectives}

The present study aimed to investigate the mediating role of marital satisfaction in the causal relationships between forgiveness and the feeling of loneliness with attitudes toward marital infidelity in married students.

\section{Materials and Methods}

This field and the correlational study included all married students at Ahvaz Branch, Islamic Azad University, Ahvaz, Iran, from October 2018 to December 2018. The sample group was selected through the convenience sampling method. Out of a total of 300 distributed questionnaires, 211 were completed and analyzed following the elimination of incomplete ones. Therefore, the sample size was estimated at 211 cases, and the data were analyzed using SPSS software (version 24) and the power index test. Inclusion criteria included at least two years of living together, avoidance of receiving any simultaneous psychological or pharmaceutical treatment, and the age range from 20 to 44 years. On the other hand, incomplete questionnaires were excluded from the study. The participants completed the questionnaires voluntarily, and written consent was obtained from them before the study. The study protocol was approved by the Ethical Committee of Ahvaz Branch, Islamic Azad University, Ahvaz, Iran. Figure 1 presents the proposed model of the research design.

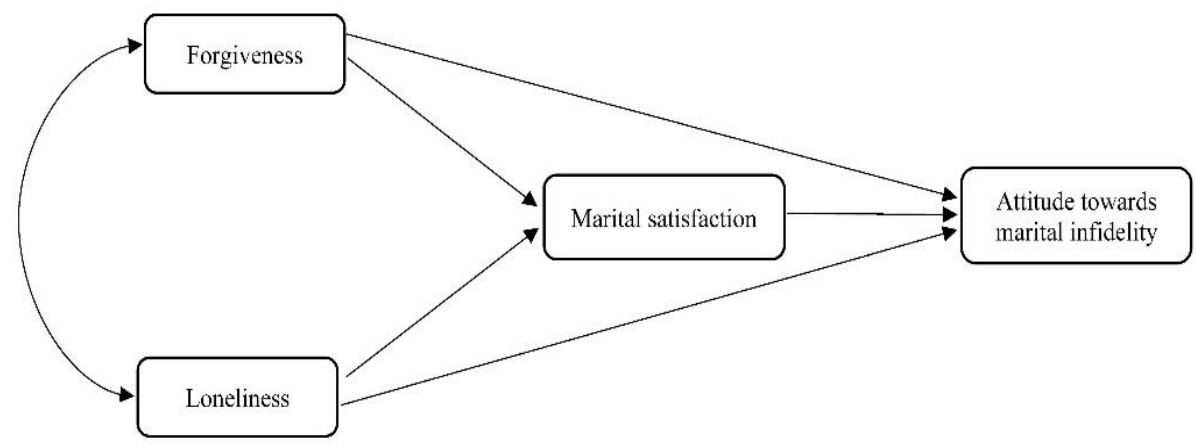

Figure 1. Proposed causal model of the study 
Instruments

Attitude towards Infidelity Scale

This 12-item scale was developed by Whatley [15] to measure the negative and positive feelings of the participants toward infidelity. This questionnaire is scored based on a 7-point Likert scale in which $1=$ "I strongly disagree", 2="somewhat disagree", $3=$ "slightly disagree", 4="I don't know", 5="slightly agree", 6="somewhat agree", and $7=$ "strongly agree". The participants were then requested to respond to the items and give scores (1-7) considering their feelings. The infidelity questionnaire evaluates the rates of willingness, acceptance, and rejection from the perspective of offenders. The highest (84) and lowest (12) scores indicated the complete acceptance and rejection of infidelity, respectively. Cronbach's alpha coefficient of the questionnaire was obtained at 0.91 [16]. However, in the present study, this corresponding value was estimated at 0.75 .

\section{Interpersonal Forgiveness Inventory}

The Interpersonal Forgiveness Inventory (IFI-25) was devised by Ehteshamzadeh et al. [17]. This 25-item questionnaire consisted of three subscales, including "Reconnection and Revenge Control", "Resentment Control", and "Realistic Understanding". The questionnaire was scored on a 4-point Likert scale. The responses to "Realistic Understanding" questions were scored on a 4-point scale in which $1=$ strongly disagree, $2=$ disagree, $3=$ agree, and $4=$ strongly agree. Moreover, "Reconnection and Revenge Control" and "Resentment Control" were reversely scored using a 4-point scale in which 4=strongly disagree, 3 =disagree, 2 =agree, and 1=strongly agree. High scores on the "Reconnection and Revenge Control" subscale indicated the individual's good ability to reconnect with the offender and a low tendency to take revenge against the other's wrongdoings. The reliability of the questionnaire was estimated at 0.78 using Cronbach's alpha for the total questionnaire [17]. In the present study, the Cronbach's alpha coefficient was determined at 0.89 for the questionnaire.

\section{Loneliness Scale}

The revised Loneliness Scale was developed by Russell et al. [18]. This 20-item questionnaire measures four subscales of "Isolation", "Socialization", "No Intimate Personal Relationships", and "No Sense of Loneliness". Moreover, the questionnaire is scored on a 4-point Likert scale in which 1="never", 2="rarely", 3="sometimes", and 4="always". However, the items of the "Socialization" subscale are scored inversely. The scores range from 20 to 80 with a mean score of 50 , and the scores higher than the mean indicate greater severity of the feeling of loneliness. Ausin et al. [19] reported a Cronbach's alpha coefficient of 0.85 . It should be noted that Cronbach's alpha coefficient of this questionnaire was determined at 0.86 in the present study.

Marital Satisfaction Questionnaire

The ENRICH Marital Satisfaction Questionnaire was designed by Olson et al. [20]. The questionnaire includes 12 subscales, including "Contract Response", "Marital Satisfaction", "Character Issues", "Marital Communication", "Conflict Resolution", "Financial Oversight", "Leisure Activities", "Sexual Intercourse", "Marriage and Children", "Relatives and Friends", "Egalitarian Roles", and "Ideological Direction Decision". The questionnaire is scored on a 5-point Likert scale in which $5=$ strongly agree, 4=agree, $3=$ neither agree nor disagree, $2=$ disagree, and $1=$ strongly disagree. Scores lower than 30, between 30 and 40, from 40 to 60 , between 60 to 70 , and above 70 indicated severe dissatisfaction, dissatisfaction, relative and moderate satisfaction, high satisfaction, and very high satisfaction with marital relationships, respectively. Cronbach's alpha coefficient was obtained at 0.73 for all questions [21]; however, in the present study, Cronbach's alpha coefficient was estimated at 0.90.

\section{Statistical analysis}

The data were analyzed in SPSS Amos software (version 24) through descriptive and inferential statistics, including mean $\pm \mathrm{SD}$, minimum and maximum scores, and Pearson correlation coefficient. Cronbach's alpha coefficient was calculated to determine reliability and validity. Moreover, the skewness and kurtosis were utilized to specify data normality, and the path analysis was used to assess the proposed model. The significance level of the research was considered to be $\alpha=0.05$.

\section{Results}

The analysis was performed on 208 individuals, and the mean \pm SD scores of attitudes towards marital infidelity, forgiveness, loneliness, and marital satisfaction were determined at 38.04 \pm 16.127 ,

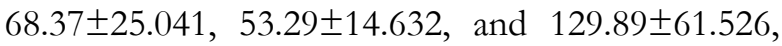
respectively. Table 1 tabulates descriptive statistics, including mean $\pm \mathrm{SD}$, as well as minimum and

Table 1. Descriptive results of the study variables $(n=208)$

\begin{tabular}{|c|c|c|c|c|}
\hline Variables & Min. & Max. & $\mathbf{M}$ & SD \\
\hline $\begin{array}{l}\text { Attitude towards marital } \\
\text { infidelity }\end{array}$ & 12 & 84 & 38.04 & 16.127 \\
\hline Forgiveness & 25 & 100 & 68.37 & 25.041 \\
\hline Loneliness & 20 & 80 & 53.29 & 14.632 \\
\hline Marital satisfaction & 47 & 235 & 129.89 & 61.526 \\
\hline
\end{tabular}




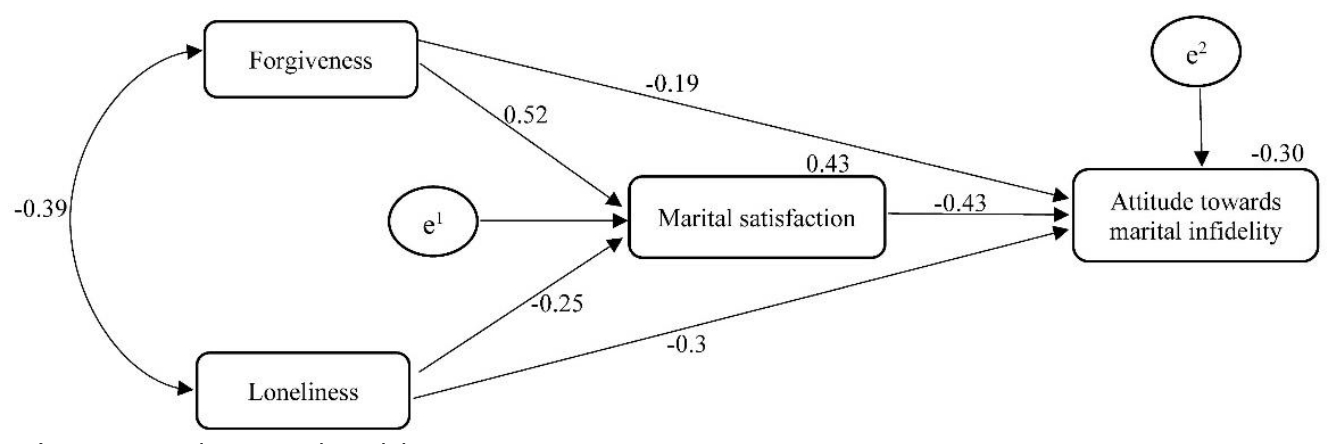

Figure 2. Initial proposed model

Table 2. Pearson correlation coefficient among variables

\begin{tabular}{lcccc}
\hline Variables & $\mathbf{1}$ & $\mathbf{2}$ & $\mathbf{3}$ & $\mathbf{4}$ \\
\hline Attitude towards & 1 & & & \\
marital infidelity & $-0.438^{* *}$ & 1 & & \\
Forgiveness & $0.236^{* *}$ & $-0.387^{* *}$ & 1 & \\
Loneliness & $-0.529^{* *}$ & $0.615^{*}$ & $-0.452^{* *}$ & 1 \\
\hline Marital satisfaction & & & &
\end{tabular}

** $\mathrm{P}<0.01$ and $* \mathrm{P}<0.05$

maximum scores of the study variables.

Pearson correlation coefficients indicated a significant negative correlation between forgiveness and attitudes towards marital infidelity $(\mathrm{r}=-0.438$, $\mathrm{P}<0.01)$ and between marital satisfaction and attitude toward marital infidelity $(\mathrm{r}=-0.529, \mathrm{P}<0.01)$. However, a positive and significant relationship was observed between the feeling of loneliness and attitudes toward marital infidelity $(r=0.236, \mathrm{P}<0.01)$. Figure 2 shows an initial proposed model that explains the attitude toward marital infidelity based on its relationship with factors, such as forgiveness, loneliness, and marital satisfaction.

The root means square error of approximation (RMSEA $=0.420$, Table 3) indicated that the initial model required modification. Therefore, the relationship between the feeling of loneliness and
Table 3. Fit indicators of the initial and final models

\begin{tabular}{lcc}
\hline Fit indicators & Initial model & Final model \\
\hline$\chi^{2}$ & 0.000 & 0.203 \\
$\mathrm{df}$ & 0 & 1 \\
$\left(\chi^{2} / \mathrm{df}\right)$ & - & 0.203 \\
$\mathrm{p}$ & - & 0.652 \\
$\mathrm{GFI}$ & 0.00 & 1.00 \\
$\mathrm{RMSEA}$ & 0.420 & 0.000 \\
\hline
\end{tabular}

attitudes toward marital infidelity was removed from the analysis. Figure 3 illustrates the final model in which RMSEA $=0.000, \quad \chi^{2} / \mathrm{df}=0.203$, and $\mathrm{CFI}=1.00$, which is indicative of a good fit of the model.

There was a significant relationship between forgiveness and attitudes toward marital infidelity $(\beta=-0.181, \quad P<0.05)$ with marital satisfaction $(\beta=0.517, \quad P<0.01) \quad($ Table 4). However, the relationship between loneliness and attitudes towards marital infidelity was not significant. Furthermore, a direct and negative relationship was observed between loneliness and marital satisfaction $(\beta=-0.252, \quad P<0.01)$. Eventually, there was a significant relationship between marital satisfaction and attitudes toward marital infidelity $(\beta=-0.418$, $\mathrm{P}<0.01)$.

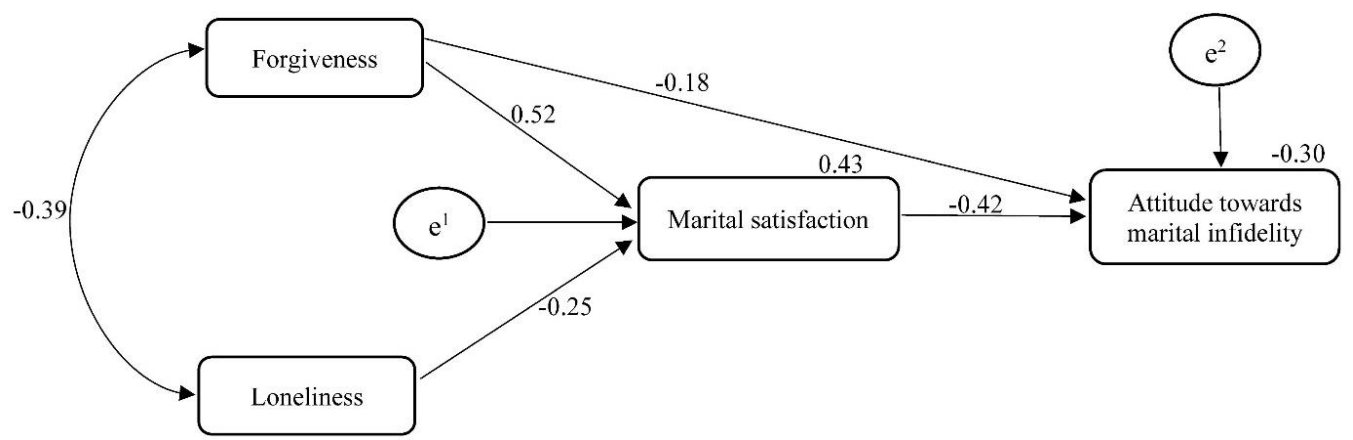

Figure 3. Final modified model

Table 4. Path coefficients for direct effects among the variables in the initial and final models

\begin{tabular}{|c|c|c|c|c|c|c|}
\hline \multirow{2}{*}{ Path } & \multicolumn{3}{|c|}{ Initial model } & \multicolumn{3}{|c|}{ Final model } \\
\hline & Path type & $\beta$ & $\mathbf{p}$ & Path type & $\beta$ & $\mathbf{p}$ \\
\hline Forgiveness and attitudes toward marital infidelity & Direct & -0.186 & 0.012 & Direct & -0.181 & 0.013 \\
\hline Forgiveness and marital satisfaction & Direct & 0.517 & 0.001 & Direct & 0.517 & 0.001 \\
\hline Loneliness and attitudes toward marital infidelity & Direct & -0.029 & 0.652 & Direct & - & - \\
\hline Loneliness and marital satisfaction & Direct & -0.252 & 0.001 & Direct & -0.252 & 0.001 \\
\hline Marital satisfaction and attitudes toward marital infidelity & Direct & -0.418 & 0.001 & Direct & -0.418 & 0.001 \\
\hline
\end{tabular}


Table 5. Results obtained from the bootstrap method to investigate the indirect and intermediary paths

\begin{tabular}{|c|c|c|c|c|c|c|}
\hline \multirow{2}{*}{ Predictor variable } & \multirow{2}{*}{ Mediator Variable } & \multirow{2}{*}{ Criterion variable } & \multicolumn{2}{|c|}{ Initial model } & \multicolumn{2}{|c|}{ Final model } \\
\hline & & & Bootstrap & P-value & Bootstrap & P-value \\
\hline Forgiveness & Marital satisfaction & Attitude towards marital infidelity & -0.169 & 0.001 & -0.165 & 0.001 \\
\hline Loneliness & Marital satisfaction & Attitude towards marital infidelity & 0.141 & 0.002 & 0.138 & 0.002 \\
\hline
\end{tabular}

The bootstrap method was adopted to determine the significance of intermediary relationships.

The indirect path of forgiveness to attitude toward marital infidelity was statistically significant regarding the mediating role of marital satisfaction $(\beta=-0.165, P<0.01)$. Furthermore, the indirect path of loneliness to attitude toward marital infidelity was significant regarding the mediating role of marital satisfaction $(\beta=0.138, \mathrm{P}<0.02)$ (Table 5).

\section{Discussion}

The present study aimed to investigate the mediating role of marital satisfaction in the causal relationships between forgiveness and a feeling of loneliness with the attitudes toward marital infidelity in married students. The results indicated that the proposed model had a good fit in this regard. In general, all direct and indirect paths showed significant relationships, except for the direct path of loneliness and attitudes toward marital infidelity. Indirect paths were also significant through marital satisfaction. Forgiveness is a process of emotional and psychological liberation in resentful people that relieves them from resentment, anger, and fear so that they no longer feel the urge to take revenge [4]. It should be noted that this is a slow process and does not necessarily mean that the person forgets his/her painful memories [22]. Forgiveness protects married females from negative interpersonal experiences and perceptions regarding marital infidelity. This protection can be achieved by diminishing the motivation to take revenge on the offending spouse, reducing rumination over the offender, avoiding improper social behavior, and increasing the chance of positive behavior toward the offender.

A sincere confession to one's mistakes and making an apology leads to forgiveness, which in turn reduces annoyance, anger, and revenge [23]. Forgiveness may lead to the reduction of destructive behaviors that result from a feeling of injustice. Moreover, it is increased in the relationship by the enhancement of empathy and kindness [24]. Spouses involved in the relationship reconstruction cycle more effectively handle the effects of damage caused to the relationship and maintain or enhance marital satisfaction [25]. The feeling of loneliness indirectly affects attitude toward marital infidelity. In other words, feeling of loneliness in individuals has a significant impact on marital satisfaction and infidelity [26]. Other factors, such as personality traits, family relationships, family performance, emotional and sexual satisfaction, self-differentiation, and other psychological factors seemed to play a role in attitudes toward marital infidelity and minimize the impact of loneliness in this study. In general, different environmental, psychological, and social factors affected the performance of people with the feeling of loneliness. Moreover, the feeling of loneliness caused a sense of sadness and notbelonging and affected one's sociability, lifestyles, as well as physical and mental health in many ways.

Couples with high levels of understanding and marital satisfaction usually experience less feeling of loneliness since they enjoy spending more time together [27]. On the contrary, couples with a lower level of marital satisfaction experience more feeling of loneliness, feel less comfortable in each other's presence, and prefer to be lonely [8]. People who avoid being close to others feel disqualified and tend to reject others when they need to be close to them. It seems that couples who suffer from loneliness may not have an intimate, trustworthy, supportive, and empathetic relationship with their spouses due to disturbed attachment during childhood and its manifestation in adulthood. Therefore, loneliness is a threat to an intimate relationship with a spouse and may reduce marital satisfaction.

The existence of a favorable level of marital satisfaction is an essential element of mental health and security in the couples' relationships. Couples who are happy and satisfied experience more satisfaction and adjustment with each other. There is less marital satisfaction, less intimacy, and no respect among couples in families with marital infidelity. The couples who have extramarital relationships no longer enjoy being together and have less adjustment in their relationships, which in turn affects the mental health of the entire family. Marital satisfaction enhances sexual and emotional health in couples, advances their ability to forgive each other during marital life, and is a great protective factor against marital infidelity [28]. Therefore, marital satisfaction plays a mediating role in the relationship between forgiveness and attitudes toward marital infidelity [29]. Moreover, it is a personal experience and can be measured by the level of enjoyment that couples experience in their marital life and depends on the individuals' expectations and desires in marriage.

Regarding the limitations of the present study, one 
can refer to its cross-sectional nature and causal explanation of correlational studies. In the present study, the sample group included married students at Ahvaz Branch, Islamic Azad University, Ahvaz, Iran. Therefore, it is difficult to generalize the results of this study to other groups and societies.

\section{Conclusions}

Marital satisfaction promotes sexual health among couples and enables them not to feel lonely in the marriage. Accordingly, loneliness and contention avoidance protect against marital infidelity. Therefore, it is reasonable to claim that marital satisfaction plays a mediating role in the association between the feeling of loneliness and attitude toward marital infidelity in a relationship.

\section{Compliance with ethical guidelines}

The present study was extracted from a Ph.D. dissertation authored by Monavar Ghazanfari Shabankare in the Department of Psychology, Ahvaz Branch, Islamic Azad University, Ahvaz, Iran. The study protocol was approved by the Ethical Committee of Ahvaz Branch, Islamic Azad University, Ahvaz, Iran (46877).

\section{Funding/Support}

This study was not funded by any agencies in the public, commercial, or non-profit sectors.

\section{Conflicts of Interest}

The authors declare that there is no conflict of interest regarding the publication of this study.

\section{References}

1. Arnocky S, Pearson M, Vaillancourt T. Health, anticipated partner infidelity, and jealousy in men and women. Evolutionary Psychology. 2015; 13(3):1-10. [DOI:10.1177/ 1474704915593666]

2. Robles TF, Slatcher RB, Trombello JM, McGinn MM. Marital quality and health: a meta-analytic review. Psychological Bulletin. 2014; 140(1):140-87. [DOI:10.1037/a0031859] [PMID] [PMCID]

3. Kruger DJ, Fisher ML, Fitzgerald CJ. Factors influencing the intended likelihood of exposing sexual infidelity. Archives of Sexual Behavior. 2015; 44(6):1697-704. [DOI:10.1007/ s10508-014-0469-x] [PMID]

4. Lichtenfeld S, Buechner VL, Maier MA, Fernбndez-Capo M. Forgive and forget: differences between decisional and emotional forgiveness. PLoS One. 2015; 10(5):e0125561. [DOI:10.1371/journal.pone.0125561] [PMID] [PMCID]

5. Kerlin AM. Women in christian substance abuse treatment; forgiveness, attachment styles, and improvements in cooccurring mental health symptoms. Journal of Religion and Health. 2019; 59(6):3168-92. [DOI:10.1007/s10943-01900948-x] [PMID]

6. Russell VM, Baker LR, McNulty JK. Attachment insecurity and infidelity in marriage: do studies of dating relationships really inform us about marriage? Journal of Family Psychology. 2013; 27(2):242-51. [DOI:10.1037/a0032118] [PMID] [PMCID]

7. Marilaf Caro M, San-Martrn M, Delgado-Bolton R, Vivanco L. Empathy, loneliness, burnout, and life satisfaction in Chilean nurses of palliative care and homecare services. Enfermeria Clinica. 2017; 27(6):379-86. [DOI:10.1016/ j.enfcli.2017.04.007] [PMID]

8. Isanejad O, Bagheri A. Marital quality, loneliness, and internet infidelity. Cyberpsychology, Behavior and Social Networking. 2018; 21(9):542-8. [DOI:10.1089/cyber.2017.0602] [PMID]

9. McNulty JK. The dark side of forgiveness: the tendency to forgive predicts continued psychological and physical aggression in marriage. Personality \& Social Psychology Bulletin. 2011; 37(6):770-83. [DOI:10.1177/0146167211
407077] [PMID] [PMCID]

10. Renna ME, Quintero JM, Fresco DM, Mennin DS. Emotion regulation therapy: a mechanism-targeted treatment for disorders of distress. Frontiers in Psychology. 2017; 8:98. [DOI:10.3389/fpsyg.2017.00098] [PMID] [PMCID]

11. Mostafazadeh P, Bahreinian SA. The relationship between personality traits and marital satisfaction with mediating positive and negative affects. Avicenna Journal of Neuro Psycho Physiology. 2018; 5(2):73-80. [DOI:10.32598/ ajnpp.5.2.73]

12. Lavner JA, Weiss B, Miller JD, Karney BR. Personality change among newlyweds: patterns, predictors, and associations with marital satisfaction over time. Developmental Psychology. 2018; 54(6):1172-85. [DOI: 10.1037/dev0000491] [PMID] [PMCID]

13. Sepahvand T. The effectiveness of integrated model of selfregulation-attachment couple therapy on dimensions of marital satisfaction of insecure couples. Avicenna Journal of Neuro Psycho Physiology. 2018; 5(4):159-68. [DOI: 10.32598/ajnpp.4.3.275]

14. McNulty JK, Wenner CA, Fisher TD. Longitudinal associations among relationship satisfaction, sexual satisfaction, and frequency of sex in early marriage. Archives of Sexual Behavior. 2016; 45(1):85-97. [DOI: 10.1007/s10508-014-0444-6] [PMID] [PMCID]

15. Whatley MA. Attitudes toward infidelity scale. Journal Social Psychology. 2008; 133(1):547-51.

16. Karini S, Yosefi R, Soliemani M. Making marital infidelity questionnaire as valid one. Clinical Psychology \& Personality. 2019; 17(1):237-48.

17. Ehteshamzadeh P, Ahadi H, Enayati MS, Heidari A Construct and validation of a scale for measuring interpersonal forgiveness. Iranian Journal of Psychiatry \& Clinical Psychology. 2011; 16(4):443-55.

18. Russell D, Peplau LA, Cutrona CE. The revised UCLA Loneliness Scale: Concurrent and discriminant validity evidence. Journal of Personality and Social Psychology. 1980; 39(3):472-80. [DOI:10.1037/0022-3514.39.3.472] [PMID]

19. Ausin B, Munoz M, Martin T, Perez-Santos E, Castellanos MA. Confirmatory factor analysis of the Revised UCLA Loneliness Scale (UCLA LS-R) in individuals over 65. Aging \& Mental Health. 2019; 23(3):345-51. [DOI:10.1080/ 13607863.2017.1423036] [PMID]

20. Olson DH, Fournier DG, Druckman JM. Counselor's manual for prepare/enrich. Minneapolis, MN: Prepare/ Enrich; 1987.

21. O'Connor $\mathrm{P}$, Izadikhah $\mathrm{Z}$, Abedini $\mathrm{S}$, Jackson CJ. Can deficits in emotional intelligence explain the negative relationship between abandonment schema and marital quality? Family Relations. 2018; 67(4):510-22. [DOI: 10.1111/fare.12320]

22. Denton RT, Martin MW. Defining forgiveness: an empirical exploration of process and role. The American Journal of Family Therapy. 1998; 26(4):281-92. [DOI:10.1080/019261 89808251107]

23. Orathinkal J, Vansteenwegen A. The effect of forgiveness on marital satisfaction in relation to marital stability. Contemporary Family Therapy. 2006; 28(2):251-60. [DOI:10.1007/s10591-006-9006-y]

24. Beckenbach J, Schmidt E, Reardon R. The interpersonal relationship resolution scale: a reliability and validity study. The Family Journal. 2010; 17(4):335-41. [DOI:10.1177] 1066480709347362]

25. Patrick S, Bechenbach J, Sells I, Reardon RF. An empirical investigation in to justice, grace, and forgiveness: Paths to relationship satisfaction. The Family Journal. 2013; 21(2):146-53. [DOl:10.1177/1066480712466540]

26. Panahi MS, Hoseinzadeh A, Razaghpour M, Hosieni N. Formulating a model for the relationship between alexithymia, social support, loneliness, and marital satisfaction: Path analysis model. Journal of Family Medicine and Primary Care. 2018; 7(5):1068-73. [DOI:10.4103/jfmpc.jfmpc_3_18] [PMID] [PMCID]

27. Hsieh N, Hawkley L. Loneliness in the older adult marriage: Associations with dyadic aversion, indifference, and ambivalence. Journal of Social and Personal Relationships. 2018; 35(10):1319-39. [DOI:10.1177/0265407517712480] 
[PMID] [PMCID]

28. Farshidmanesh F, Davoudi H, Heidari H, Bahramabadi MZ. Comparison of the effectiveness of the schema therapy training and mindfulness on intimacy, commitment, and happiness of women with couple burnout. International Archives of Health Sciences. 2019; 6(4):136-42. [DOI:10.4103/iahs.iahs_51_19]
29. Cao H, Zhou N, Fine MA, Li X, Fang X. Sexual satisfaction and marital satisfaction during the early years of Chinese marriage: a three-wave, cross-lagged, actor-partner interdependence model. The Journal of Sex Research. 2018; 56(3):391-407. [DOI:10.1080/00224499.2018.1463503] [PMID] 